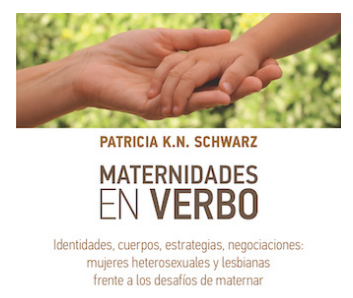

Schwarz PKN. Maternidades en verbo: identidades, cuerpos, estrategias, negociaciones: mujeres heterosexuales y lesbianas frente a los desafíos de maternar. Buenos Aires: Editorial Biblos; 2016.

\section{Maternidade en el nuevo siglo}

En "Maternidades en verbo. Identidades, cuerpos, estrategias, negociaciones: mujeres heterosexuales y lesbianas frente a los desafíos de maternar", el libro de Patricia K.N. Schwarz publicado por Editorial Biblos, la maternidad es abordada como temática que se despliega en la " $[\ldots]$ arena política de definición de espacios de poder" (p. 17). El libro, que se terminó de escribir en 2014, reúne los hallazgos de dos investigaciones empíricas (o de una investigación en dos etapas). La primera - realizada entre 2005 y 2010 - consiste en una investigación cualitativa basada en entrevistas, grupos focales y observaciones a mujeres heterosexuales y lesbianas de 25 a 35 años de sectores medios, y entrevistas a médicos y médicas ginecólogos y obstetras, en la Ciudad de Buenos Aires. La segunda -realizada entre 2011 y 2012 como consecuencia del interés que provocó en la autora la sanción de la ley 26.618/2010 de Matrimonio Igualitario para poner en diálogo los hallazgos iniciales- consiste en una investigación cualitativa basada en entrevistas a mujeres lesbianas de 25 a 38 años de sectores medios en la Ciudad de Buenos Aires.
La consideración de la normativa mencionada, además de las puertas abiertas a la investigación, responde a la mirada teórica y política desde la perspectiva de derechos presente a lo largo de las páginas del libro. En la Argentina, a partir de 1983, con disímiles estridencias y énfasis en las agendas, los temas de derechos sexuales y reproductivos salieron definitivamente del ostracismo y, si bien con deudas pendientes para con la sociedad -especialmente para con las mujeres-como en el caso del aborto, la sanción de la ley 26.618/2010 colocó a la Argentina como primer país sudamericano en legalizar los matrimonios entre personas del mismo sexo. Desde todo punto de vista, para una estudiosa de la experiencia de la maternidad/ maternazgo, ese hecho político era insoslayable.

La reflexión teórica y la búsqueda analítica de Patricia K.N. Schwarz fueron pensadas desde los procesos contradictorios y paradojales de la modernidad tardía y ancladas en un minucioso andamiaje teóricoconceptual feminista y de género. En los capítulos analíticos, la autora buscó responder a interrogantes sobre la maternidad y sus cambios en la sociedad contemporánea a través de un doble movimiento: el de la experiencia de la maternidad y el de la
Mónica Petracci(a)

$$
\begin{array}{r}
\text { (a) Instituto Gino } \\
\text { Germani, Facultad } \\
\text { de Ciencias Sociales, } \\
\text { Universidad de Buenos } \\
\text { Aires. Dirección: Pte. J. } \\
\text { E. Uriburu, 950, 60 piso, } \\
\text { C1114AAD. Ciudad de } \\
\text { Buenos Aires, Argentina. } \\
\text { mnpetracci@gmail.com }
\end{array}
$$


significación de la maternidad para la identidad genérica, esa identidad provocadora de la inquietud que llevó a la autora a la escritura, tal como lo anuncia en las primeras líneas del libro.

Varios interrogantes sobre la maternidad guiaron la investigación:

[...] ¿cuáles son los entramados normativos a los que las mujeres responden cuando deciden tener un hijo? ¿cuál es la configuración identitaria genérica que dialoga con ello?, ¿cómo interviene la iterabilidad normativa en la performance de las mujeres en lo que a la maternidad se refiere?, ¿es posible desandar el camino de la maternidad compulsiva?, ¿cuál es la construcción significativa que articula la maternidad con la identidad genérica de las mujeres?, ¿qué actores constituyen la red intersubjetiva de experiencia en el campo de la maternidad? (p. 23-4)

A través de cinco capítulos analíticos del material cualitativo relevado que reseñaré, brevemente, a continuación, en el libro se enhebran la relevancia otorgada a la temática desde siempre y en la sociedad contemporánea; los cuerpos; las voces plurales de las mujeres y de los.as profesionales de la salud y la riqueza de sus respuestas; las configuraciones mutuas de la maternidad y la identidad; las prácticas sociales traducidas como estrategias y negociaciones. $Y$ vuelvo al título del libro a través de una pregunta cuya respuesta retomaré más adelante: ¿es maternar un desafío?.

"Socialización de género en la trayectoria de las mujeres", capítulo en el que la autora desde su formación sociológica- observa cómo el proceso socializador que refuerza estereotipos de género atraviesa con especificidades las trayectorias de vida de las mujeres pero que, a su vez, presenta "destellos" (p.121) no conflictivos y con sutiles diferencias para la búsqueda de experiencias múltiples, la legitimidad de la participación de la mujer en el mercado laboral, la individuación de la experiencia materna y de la mujer en tanto sujeto.

Identidad genérica y maternidad", capítulo en el que la autora observa cómo la construcción de la identidad de las mujeres estudiadas se encuentra enredada en una paradoja: " [...] existe una puja de fuerzas entre el aparato de significados 'madre' (que encierra la figura mítica de 'madre' o condición maternal) versus el aparato de significados 'mujer' (que se conecta con la construcción de inteligibilidad en tanto sujeto de la modernidad tardía)" (p. 141).

En el capítulo, en síntesis, se complejiza el análisis de la vigencia de las estructuras normativas de sujeción de la mujer.

"La maternidad en acción", capítulo en el que la autora refiere a las percepciones $y$, fundamentalmente a las prácticas, mencionadas por las entrevistadas acerca de la maternidad. $Y$ es allí donde, con nitidez, aparecen los cuerpos de las mujeres como escenarios de otras prácticas. Estas últimas, las prácticas del poder, no son más que las acciones de los sectores más conservadores de la sociedad, en todas sus instancias, para impedir cambios y logros en temas de derechos sexuales y reproductivos. "El día tiene veinticuatro horas: maternazgo y construcción de la identidad individual", capítulo en el que la autora refiere a la persistencia de visiones esencialistas en distintos campos hegemónicos y resalta la sobrecarga generada por la denominada doble jornada de actividad en paralelo con otras exigencias como disponer de tiempos propios.

"Un nuevo escenario para el proyecto y la práctica de las maternidades: la ley de Matrimonio Igualitario y las maternidades lesbianas", capítulo en el que la autora completa su línea investigativa para "[...] establecer una nueva aproximación a la luz de los datos previamente construidos" (p. 251). Si bien la autora, en el inicio del capítulo, aclara que la profundidad del tema no será complejizada, sienta las bases para visibilizar identidades, cuerpos y prácticas con las cuales dialogó a lo largo del análisis. Abrió un diálogo. Desde mi perspectiva, una puesta en diálogo es enriquecedora respecto de la narración analítica comparativa de respuestas sobre la maternidad de mujeres heterosexuales y lesbianas por la distancia temporal entre las dos investigaciones, y por la necesidad teórica argumentativa que la comparación requiere.

A lo largo de los capítulos queda claro que la autora está lejos de considerar a la maternidad como algo natural pero que, a su vez, de acuerdo 
al análisis de las entrevistas, la construcción social y política que visibiliza busca - como siempre lo ha hecho y la autora lo destaca- mantener el mito de la mujer-madre en el proyecto individual. Dicho en otras palabras: la normativa genérica persiste.

Indudablemente, "maternar" es un desafío para la autora, y el libro un reto que Patricia K.N. Schwarz hace al lector.a:

[...] Me gusta pensar en este libro como un micrófono abierto, una ventana de oportunidad para reflexionar juntos con el lector acerca de las cosas que se nos juegan a mujeres y varones en esto de ser madres, padres, hijos. [...] Si este libro despierta en el lector una inquietud, que empuje, que moleste y que lo lleve a buscar más, el objetivo que me propongo estará cumplido. (p. 18-19)

Pienso que el libro consigue su propósito. Tanto estudiosas y estudiosos de estas temáticas, y también otros públicos como tomadores de decisión, periodistas y comunicadores sociales, representantes y militantes de organizaciones no gubermantales encontrarán en "Maternidades en verbo. Identidades, cuerpos, estrategias, negociaciones: mujeres heterosexuales y lesbianas frente a los desafíos de maternar", el libro de Patricia K.N. Schwarz publicado por Editorial Biblos, es una contribución al conocimiento y el debate. 
